\title{
EL PRINCIPIO DE LEGALIDAD FORMAL BAJO EL PRISMA DE LA CONSTITUCiÓN "NORMATIZADA" "
}

Roberto Omar Berizonce***

\section{RESUMEN}

A partir de la indagación de la operancia del derecho fundamental a la tutela judicial eficiente en los ordenamientos procesales, se persigue acreditar su incidencia sobre la teoría de la jurisdicción y, especialmente, en relación al régimen de las formas procesales. Abordaje que se realiza valiéndose de métodos empírico-valorativos, e histórico-comparativo, contemplando el íntegro sistema de justicia bajo el perfil de su efectividad y su adecuación a los requerimientos de una sociedad en constante transformación, proyectada hacia la construcción de un orden social más justo. Los resultados de la indagación resaltan una renovada concepción que conjuga armoniosamente los postulados de legalidad y adecuación flexible y elástica de las formas procesales, para concluir en la necesidad de conceder a los jueces atribuciones limitadas, aunque suficientes, para ordenar razonablemente los desarrollos litigiosos con la finalidad de su simplificación y aceleración, presupuestos ineficientes de la tutela judicial efectiva.

Palabras clave: Tutela judicial eficiente, legalidad formal, adecuación y flexibilización, poderes del juez.

Fecha Recibido: marzo 31 de 2014 - Fecha Aceptado: mayo 26 de 2014

* Artículo inédito.

*: Decano de la Facultad de Ciencias Jurídicas y Sociales de la Universidad Nacional de La Plata (2001-2004), profesor de la misma Casa de Estudios. Director de la Carrera de Postgrado en Derecho Procesal Profundizado en la Universidad Notarial Argentina (1991-2001), Presidente Honorario del Instituto Iberoamericano de Derecho Procesal y miembro de la Asociación Internacional de la especialidad. Autor de numerosas obras. 


\begin{abstract}
From the investigation of the operation viability in the fundamental right to effective judicial protection in the procedural rules, the aim is to prove their impact on the theory of jurisdiction, and especially in relation to the regime of procedural forms. Approach that is performed using empirical-valuation methods, and historical-comparative, looking at the whole system of justice under the profile of its effectiveness and its relevance to the requirements of a society in constant transformation, projected towards the construction of a social order more fair. The results of the inquiry highlighted a renewed conception that harmoniously combines the principles of legality and appropriateness of flexible and elastic procedural forms, to conclude on the need for limited powers granted to judges, although sufficient to reasonably sort contentious developments with purpose of simplification and acceleration, inefficient estimates of effective judicial protection.
\end{abstract}

Key words: Effective judicial protection, formal legality, suitability and flexibility, powers of the judge.

\title{
INTRODUCCIÓN.
}

\section{LEGALIDAD E INSTRUMENTALIDAD DE LAS FORMAS}

Tal como se expresa en la clásica enseñanza de Calamandrei ${ }^{1}$, las formas procesales no sirven, como podrían pensar los profanos para hacer más complicado y menos comprensible el desarrollo del proceso, sino por el contrario, para hacerlo más simple y claro... en lugar de un embarazo para la justicia son en realidad, una preciosa garantía de los derechos y las libertades individuales. El devenir histórico del proceso judicial muestra, sin embargo, un constante ir y venir, un movimiento pendular que a lo largo de los siglos transcurre alternativamente desde la entronización del formalismo -y aún de su desfiguración, el formulismo- a la del principio opuesto de un ilusorio ideal de la libertad absoluta de las formas, un proceso sin formas preordenadas en aquel momento tan singular de la historia de la humanidad que alumbra con la Revolución Francesa.

En el proceso contemporáneo terminó prevaleciendo de modo indisputado el principio de legalidad, como una suerte de rígido mecanismo estatuido por el legislador en la letra de la normativa procesal que, sin embargo, en su

1 Instituciones de Derecho Procesal Civil, Ejea, Bs. As., 1943, trad. S. Sentís Melendo, v. I, p. 246. 
desenvolvimiento, se ha ido matizando al punto de flexibilizarse, y aún transmutarse fundiéndose con otras pautas o criterios de algún modo contrapuestos como son los de instrumentalidad o finalismo, elasticidad o adecuación de las formas. Todavía, en ciertos supuestos de excepción, se afirma una cierta tendencia a la desformalización limitada.

En el proceso civil, el esquema de la legalidad pura tiene su apoyo y se articula al cobijo de la concepción del principio dispositivo a ultranza, donde el juez funge como verdadero "convidado de piedra", figura pasiva, impasible e inerte no solo para la conducción y ordenación de los trámites y la instrucción probatoria, sino aún por la atadura a las pruebas tasadas ${ }^{2}$. De ahí que a la progresiva atenuación del principio dispositivo se sigue como correlato, el necesario reconocimiento de potestades judiciales, en grado e intensidad diversa, sea para: i) exonerar la inobservancia de las formas cuando se ha cumplido, de una u otra manera, la finalidad del acto (principio de instrumentalidad o finalismo); ii) fijar por sí aquellas reglas que fueran legalmente disponibles (disponibilidad de las formas); iii) adecuar las formas a las particularidades del caso, flexibilizando las reglas legales o fijándolas directamente, adoptando cualquier modo apto conducente a la obtención de su fin (adecuación, elasticidad o flexibilidad de las formas).

1) El principio de instrumentalidad o finalismo, recogido como notorio avance en el CPCN argentino de $1967^{3}$, pone el acento en la premisa que las formas no constituyen un fin en sí mismas. De ahí que el cumplimiento de la finalidad del acto impide la declaración de su nulidad, no obstante su irregularidad y aun cuando carezca de alguno de sus requisitos (art. 169). Lo que es lo mismo, que es válido en tanto se haya realizado de cualquier modo apropiado para la obtención de su objetivo. La finalidad no ha interpretarse desde el punto de vista subjetivo, sino objetivo, en relación a la función que cabe asignar a cada acto. Lo que es fundamental, las finalidades particulares se subsumen en la necesidad de asegurar la inviolabilidad de la defensa, finalidad genérica de todos los actos del proceso $^{4}$. Precisamente, de la riqueza

2 CAPPELLETTI M., El testimonio de la parte en el sistema de la oralidad, LEP, La Plata, 2002, trad. T.A. Banzhaf, parte primera, pp. 271 y ss. DENTI V., Estudios de derecho probatorio, Ejea, Bs. As., 1974, trad. S. Sentís Melendo y T.A. Banzhaf, pp. 1009-118.

3 Como se expresa en la Exposición de motivos de la ley 17.454, la fórmula adoptada responde a la establecida en el art. 156 del CPC italiano, acogida también por ordenamientos provinciales de La Rioja (art. 241), Mendoza (art. 94.I), Jujuy (art. 179) y Santa Fe (art. 128, inc. 1). MORELLO A.M., PASSI LANZA M.A., SOSA G.L., BERIZONCE R.O., Códigos Procesales..., v. I., pp. 647 y ss., v. II-C, pp. 323 y ss.

$4 \quad$ PALACIO L.E., Derecho Procesal Civil, Abeledo-Perrot, Bs. As., 1972, v. IV, pp. 144-145. 
de este enunciado se ha derivado el fundamento esencial de la doctrina del exceso ritual manifiesto, elaborada por la CSN: las formas no pueden impedir el acceso a la verdad y a la justicia.

2) La propia ley procesal habilita de modo expreso ciertos actos de autoridad del juez para determinar, a través de providencias ordenatorias, el trámite correspondiente en atención a las particularidades del caso, seleccionando uno más apto entre los tipos legales alternativos. Así en las tercerías (art. $101 \mathrm{CPCN}$ ); en la acción meramente declarativa (art. 322); en la determinación de los daños y perjuicios derivados de las medidas cautelares (art. 208); en el trámite de la ejecución de sentencia en supuesto de condena a entregar cosas que no puede cumplirse (art. 515); en la liquidación de sociedades, incluida la determinación del carácter de los bienes de la sociedad conyugal (art. 516, 514). En las causas iniciadas en ejercicio de los derechos de consumidores o usuarios regirán las normas del proceso de conocimiento más abreviado, a menos que a pedido de parte el juez por resolución fundada y basado en la complejidad de la pretensión, considere necesario un trámite de conocimiento más adecuado (art. 53, ley 24.240, texto ley 26.361). En esos supuestos, corresponde al juez señalar en la primera providencia instructoria cuál ha de ser la vía o tipo procesal por la cual se canalizarán dichas pretensiones, preservando naturalmente la garantía de la defensa. La habilitación que proviene de la propia ley procesal resulta acotada, en cuanto las atribuciones del juez se limitan a escoger una de entre las distintas vías normadas. No puede determinar una diversa ni, tampoco, articular un procedimiento abierto innominado con el solo argumento que lo considera más apto para el logro de las finalidades perseguidas.

En una lectura estricta del sistema del CPCN, en consecuencia, solamente esas, así acotadas, serían las concesiones "elásticas" a los poderes ordenatorios del juez. Hemos de ver, sin embargo, cómo por vía de la interpretación creativa pretoriana se han abierto paulatinamente nuevos cauces en una línea de avance que, haciendo pie en las garantías fundamentales del debido proceso, primero -doctrina de la arbitrariedad de sentencia por excesivo rigor formal- y de la tutela judicial efectiva, después, permite aseverar que el principio de adecuación judicial de las formas, en los márgenes y con las limitaciones que hemos de ver, integra el sistema formal argentino. La experiencia de novedosas instituciones que muestra el derecho comparado, pone en evidencia que existe una vigorosa tendencia en ese sentido. Basta mencionar los mecanismos de case management y las potestades reconocidas al juez para seleccionar los tipos procesales más adecuados, originarios de 
la legislación anglosajona ${ }^{5}$ y presentes ahora también, en buena medida y con variantes, en los ordenamientos de la tradición del civil law continental europeo $^{6}$, como acaece en Italia donde resalta la reciente articulación de los procesos sumarios o simplificados 7 . Todavía, poderes de gestión similares se acuerdan a partir de contratos de procedimiento del ordenamiento francés, que posibilitan un programa de actividades acordado por el juez y las partes, facilitando la gestión colaborativa de la instancia ${ }^{8}$. Movimiento tendencial que se ha reflejado en nuestro país, por otra parte, en prestigiosa doctrina autoral, particularmente en relación a los poderes de gestión judicial ${ }^{9}$.

\section{EL PRINCIPIO DE LEGALIDAD BAJO EL PRISMA CONSTITUCIONAL (Y CONVENCIONAL)}

Del encumbramiento en el vértice de la escala valorativa del derecho a la tutela judicial efectiva, que proviene de los textos constitucionales sancionados en Argentina en 1994 y del Pacto de San José de Costa Rica, tanto como de la interpretación jurisprudencial ${ }^{10}$, se deriva necesariamente un profundo

5 JOLOWICZ A., Il nuovo ruolo del giudice del "pre-trial" nel processo civile inglese en RTDePC, 2003, p. 1263. BARBOSA MOREIRA J.C., Uma novidade: o Código de Processo Civil inglês en Temas de Direito Processual, Sétima Série, Saraiva, Sâo Paulo, 2001, pp. 179 y ss. ANDREWS N., Relaçôes entre a Corte e as partes na era no case management, en RePro, $\mathrm{n}^{\circ} 217,2013$, pp. 181 y ss.

6 BIAVATI P., Tendencias recientes de la justicia civil en Europa, RDP 2008-1, p. 540; id., Argomenti di Diritto Processuale Civile, Bonomia Univ. Press, Bologna, 2011, pp. 100 y ss.

7 Ley 69, del 18 de junio de 2009, que introdujera los arts. 702 bis, 702 ter y 702 quater. BIAVATI P., Op. cit., p. 516; id., Apuntes introductivos sobre el nuevo proceso de cognición simplificada, RDP, 2010-1, p. 541 y ss. SALETTI A. y SASSANI B., Commentario alla reforma del Códice di Procedura Civile (Legge 18 giugno, 2009, $n^{\circ}$ 69), Utet, Torino, 2009, pp. 227 y ss.

8 CADIET L., Las nuevas tendencias del procedimiento civil en Francia en Reforma procesal civil, E. Oteiza coord., AADP, Rubinzal Culzoni ed., Bs. As., 2009, pp. 109-111.

9 Así, en las ponencias presentadas y ulteriores debates en el Congreso Nacional de Derecho Procesal, Bs. As., 2009: XXV Congreso Nacional de Derecho Procesal. Ponencias generales..., AADP, Bs. As., pp. 206 y ss.; 214 y ss.; 240-347.

10 El derecho a la tutela judicial efectiva había sido explícitamente receptado por la CSN argentina ya en 1992 en el caso "Ekmekdjian M.A. c. Sofovich G. y otros", donde se sostuvo que su fundamento radica en "la idea directriz de nuestro ordenamiento constitucional -que emerge de la garantía del debido proceso- cual es el principio pro actione a que conduce el derecho fundamental a la tutela judicial efectiva, que se deriva, necesariamente, del art. 18 de la CN, cuya regulación se integra, además, con las disposiciones del Pacto de San José de Costa Rica, ...que tiene el carácter de Ley Suprema de la Nación..." (Fallos, 315:1492, consid. 15). 
replanteo que conmueve los cimientos mismos del derecho procesal ${ }^{11}$. No es solo un derecho fundamental -la eficaz prestación de los servicios de justicia (art. 114, párrafo tercero, apart. 6, CN) o la tutela judicial continua y efectiva (art. 15, C Prov. Bs.As.)-, sino uno de los más trascendentes, por constituir el derecho a hacer valer los propios derechos. Integra los genéricamente denominados derechos o garantías fundamentales materiales y formales de la organización y del procedimiento, destinadas a la realización y aseguramiento de los (demás) derechos fundamentales ${ }^{12}$.

En el marco de una inédita tendencia hacia la construcción de un "constitucionalismo global" para la tutela de los derechos fundamentales ${ }^{13}$, se asiste al afianzamiento de la concepción de la justicia civil como manifestación de una de las funciones públicas esenciales del Estado democrático de derecho, o Estado "de justicia", con sus correlatos del aseguramiento de las garantías fundamentales del proceso y su efectividad en concreto (la "edad" de las garantías, como gustaba expresar MORELLO), en consonancia con su "constitucionalización"14 y “convencionalización”. De ello se deriva, entre otros fenómenos, el de las novedosas tutelas procesales diferenciadas, que introducen jurisdicciones y técnicas procesales especiales para brindar protección a sujetos y situaciones que las propias constituciones o pactos afirman con particular énfasis en el catálogo del bill of right sustantivo -derechos a la vida, a la dignidad, a la salud, a la educación y, en general, económicos, sociales y culturales (DESC), incluyendo aquellos de incidencia colectiva-. En semejante contexto deviene inevitable el reconocimiento de nuevas y más prominentes misiones de los jueces, como activistas gestores, ejecutores y garantes de la efectividad de tales garantías y,

11 GOZAINI considera que existe un "neoprocesalismo" que tiende a crear un emplazamiento renovado para la disciplina procesal (El "neoprocesalismo", La Ley, 2005 - E, p.1328; también en Rev. Iberoam. Der. Proc., Bs. As., 2006, n 9, p. 227 y ss.). CAMBI, E., Neoconstitucionalismo y neoprocessualismo en Processo e Constituiçâo. Estudos em homenagem ao Prof. José Carlos Barbosa Moreira, L. Fux y ot., coord., RT, São Paulo, 2006, pp. 662 y ss.

12 ALEXY R., Teoría de los derechos fundamentales. Centro de Est. Polit. y Const., Madrid, 2002, 3a. reimpresión, trad. E. Garzón Valdés, pp. 454-459, quien destaca que en la discusión actual sobre derechos fundamentales ninguna idea ha despertado tanto interés como la de la conexión entre derechos fundamentales, organización y procedimiento.

13 GILLES P., El proceso civil en transformación..., RePro, Sâo Paulo, nº 173, 2009, pp. 330 y ss. Movimiento, por otra parte, anticipado por CAPPELLETTI M. (Acceso a la justicia (como programa de reformas y como método de pensamiento), Rev. Col. Abog. La Plata, 1981, n 41 , pp. 153-154).

14 MARINONI L.G., Teoría geral do processo, E. dos T., Sâo Paulo, 2006, pp. 101-139; 451-467. ZANETTI Jr. H., O modelo constitucional do processo civil brasileiro, Lumen Juris, R. de Janeiro, 2007, pp. 177-184. 
por consecuencia, el papel ya indisputado de la jurisprudencia como verdadera y propia fuente del derecho ${ }^{15}$.

Los principios procesales sufren, por ende, significativas mutaciones derivándose en general una pronunciada atenuación o flexibilización del principio dispositivo y, en paralelo, el reforzamiento de los deberes de cooperación y buena fe a cargo de las partes, el acentuamiento de la celeridad y economía procesal, la flexibilización de la preclusión y de la congruencia, condiciones todas ellas necesarias para el dictado de una sentencia justa sustentada en la realidad litigiosa, en el marco de una justicia de resultados. El proceso civil se conforma por lo que se ha dado en denominar paradigma del "formalismo valorativo" 16 .

Tan complejo y abarcador fenómeno, con sus múltiples aristas, incide decisivamente en el sistema de legalidad de las formas, en especial por conducto de la interpretación pretoriana de los renovados y reafirmados contenidos de la tradicional garantía del debido proceso, ahora amplificada y transmutada en el derecho fundamental a la tutela judicial efectiva ${ }^{17}$. Entre sus alcances, al menos y no taxativamente, están comprendidos: (i.) el debido proceso, como oportunidad de ser oído y probar en contradictorio, en cualquier proceso para la determinación de los derechos y obligaciones de orden civil, laboral, fiscal o de cualquier otro carácter; (i.i.) el libre e irrestricto acceso a la jurisdicción, enfatizado cuando están en juego derechos de tutela preferente; (i.i.i.) las debidas garantías del procedimiento, que incluye la operancia del contradictorio en todas sus facetas, instancias y procedimientos; y también las garantías de

15 MARINONI L.G. Op. cit., pp. 101-139. BERIZONCE R.O. Tutelas procesales diferenciadas, Rubinzal Culzoni ed., Santa Fe, 2009, passim.

16 El proceso -se afirma- ha de organizarse, no solo en cuanto a las formas sino especialmente a través de la delimitación de los poderes, facultades y deberes de los sujetos, coordinación y ordenación de los trámites, con vistas a que sean alcanzadas sus finalidades primordiales (ALVARO DE OLIVEIRA C.A., Del formalismo en el proceso civil (propuesta de un formalismo-valorativo), Palestra, Lima, 2007, trad. J. J. Monroy Palacios, passim). En sentido similar, complementariamente, se considera las formalidades como garantía orgánica de equilibrio dialógico de poder, destacándose la importancia del contradictorio como salvaguarda del avance de los poderes del juez (CABRAL A. do Passo, Nulidades no processo moderno, Forense, R. de Janeiro, 2a . ed., 2010, pp. 175 y ss.). Asimismo: BIAVATI P., Argomenti..., Op. cit., pp.100-102, donde se resalta la observancia del derecho de defensa y la independencia del juez como ingredientes que confluyen al diálogo entre el juez y las partes, en el tránsito a la flexibilización razonable y adecuada en los casos concretos.

17 MORELlO A.M., Constitución y proceso..., Abeledo-Perrot, LEP, Bs. As., 1998, passim; id., La eficacia del proceso, Hammurabi, Bs. As., 2001, 2a.ed., passim; id., El proceso justo, Lexis Nexis, LEP, Bs. 2005, 2a. ed., pp. 335 y ss. 
igualdad efectiva que conduce a la igualación en concreto de las partes, cuando se controvierten derechos de protección diferenciada; (i.i.i.i.) una sentencia "intrínsecamente" justa, sustentada en la verdad jurídico objetiva y no tributaria de un excesivo rigor formal; (i.i.i.i.i.) y dictada dentro de un plazo razonable; (i.i.i.i.i.i.) la ejecución efectiva de la sentencia para remover la resistencia del obligado; y (i.i.i.i.i.i.i.) las medidas cautelares, urgentes y anticipatorias necesarias sea para asegurar el cumplimiento de la sentencia, ya como decisión provisional anticipada de mérito.

Ahora bien, ante la fuerza normativa -"normativización"- de la Constitución y su carácter exorbitante y abarcador, la ley y los códigos -entre ellos, los ordenamientos procesales- han dejado de ocupar en su textualidad el centro y el corazón del sistema jurídico, quedando ahora subordinados a los valores y principios que emanan de aquella ${ }^{18}$. Las reglas procesales estampadas en el código no pueden ser leídas en clave de su sola y dogmática textualidad, sino, antes bien, en función de tales valores y principios, que se resumen y compendían en los contenidos, antes referidos, de la tutela judicial efectiva. El juez no se limita ya, simplemente, a actuar la voluntad de la ley, sino que su misión en la interpretación y aplicación de la normativa procesal, reside más bien en tornar efectiva la tutela jurisdiccional de los derechos, en el marco, naturalmente, de la observancia de las garantías del proceso -contradictorio, publicidad, fundamentación suficiente del decisorio, razonabilidad, consistencia-.

\section{LA DOCTRINA PRETORIANA DEL EXCESO RITUAL MANIFIESTO}

La doctrina acuñada por la CSN argentina para descalificar por arbitrariedad los pronunciamientos que, por tributarios de un excesivo rigor formal, frustran la aplicación del derecho en los casos concretos con menoscabo de la justicia intrínseca, se ha construido sobre supuestos paradigmáticos en que la preceptiva procedimental, en su pura textualidad, se erigía en obstáculo insalvable para satisfacer el imperativo de la justicia. Donde el conflicto entre la norma formal y la garantía fundamental -la del debido proceso y, ahora, la de la tutela judicial efectiva-, se dirimía a favor de la textualidad, con renuncia conciente a la posibilidad de dirimir el conflicto con justicia. Desde los albores de la creación pretoriana ya se predicaba magistralmente que "el proceso civil no puede ser conducido en términos estrictamente formales, (pues) no se trata ciertamente del cumplimiento de ritos caprichosos sino de procedimientos destinados al establecimiento de la verdad jurídica objetiva, que es su norte". La sentencia

18 MARINONI L.G., El proceso en el Estado constitucional, en Rev. Peruana de Derecho Procesal, Communitas, Lima, 2010, trad. Ch. Delgado Suaréz, pp. 177 y ss. 
debe ser la aplicación de la ley a los hechos del caso, y no la frustración ritual de la aplicación del derecho ${ }^{19}$. Y donde la ley procesal literalmente establece que el juez podrá, a esos efectos, disponer las diligencias de prueba necesarias para esclarecer la verdad de los hechos controvertidos, semejante potestad debe interpretarse que se convierte en imperativa, de irrenunciable ejercicio - no sólo podrá sino que deberá hacerlo-, toda vez que se trate de pruebas decisivas, cuya eficacia resulta indudable para la justa decisión de la causa ${ }^{20}$. Con lo que el tribunal reescribe el precepto del art. 36 inc. 2, CPC, convirtiendo en deber lo que era literalmente una simple facultad judicial. Claro que, rápidamente se ocupó después de acotar razonablemente los alcances de su propia doctrina, subrayando que la causal de excesivo rigorismo no supone soslayar el riguroso cumplimiento de las formas procesales, sino que pretende contemplar la desnaturalización de su uso en desmedro de la garantía de la defensa ${ }^{21}$.

No es el propósito de este análisis desarrollar la extensa casuística en torno de tal doctrina. En todo caso, interesa destacar un señalamiento significativo, el de ver su particular operatividad en los supuestos de tutelas procesales diferenciadas de los derechos fundamentales cuya protección encarece el bill of right constitucional y convencional, en el marco de un deber genérico de aseguramiento positivo (art. 75 inc. 23, CN argentina y disposiciones concordantes en el derecho internacional de los derechos humanos). Así, por caso, cuando estaba en juego el acceso a la justicia, comprometido por la aplicación literal de las normas que regulan el beneficio de litigar sin gastos y la admisibilidad en esos casos de los recursos extraordinarios ${ }^{22}$. O tratándose de derechos sociales derivados del trabajo, la admisión bajo el manto de una medida cautelar de una verdadera y propia tutela anticipada ${ }^{23}$. O en materia de seguridad social, donde ha de regir un criterio amplio para la apreciación de las cuestiones formales, de modo que el hecho de no haberse acreditado la personería en el término del art. $48 \mathrm{CPCN}$, no puede perjudicar los derechos de contenido alimentario que cuentan con la tutela jurisdiccional ${ }^{24}$. O cuando en punto al acceso a las instancias extraordinarias locales, se han flexibilizado

\footnotetext{
19 CSN, Fallos, 238:550.

20 CSN, Fallos, 302:1611. Por todos: BERTOLINO P.J., El exceso ritual manifiesto, LEP, La Plata, 2003, 2a . ed., passim.

21 CSN, Fallos, 307:739, entre muchos.

22 CSN, Fallos, 308:135, entre otros.

23 CSN, 7-8-97, "Camacho Acosta”. Asimismo, en situaciones de incapacidad, carencia de medios económicos y riesgos de vida tratándose de una acción de daños, por la necesidad de poner el acento en el valor eficacia de la función jurisdiccional (6-12-2011, "Pardo H.P. y ot."). CSN, 26-10-99, “Aquerreta H. c. ANSES, s/reajuste por movilidad”.
} 
normas formales de admisibilidad, evitando todo exceso ritual (definitividad, restricción por el monto en disputa), si estaban involucrados derechos fundamentales, con sustento en estándares como el de resguardo de la salud y el bienestar, el interés superior del niño, la protección integral de la familia y, en general, los derechos sociales de raíz alimentaria ${ }^{25}$.

La Casación de la Provincia de Buenos Aires ha ido todavía más lejos al transformar en asuntos como los que nos ocupan la competencia negativa típica de su intervención en la decisión del recurso extraordinario de nulidad, asumiendo además competencia positiva. Así, ha decidido que si bien corresponde declarar de oficio la nulidad de la sentencia por infracción al art. 168 de la Constitución Provincial, el tribunal no puede desentenderse de las circunstancias del caso de las que resulta patente que se encuentra en riesgo la salud de un menor a quien debe brindársele urgente atención, por lo que asumiendo competencia positiva corresponde disponer las medidas cautelares previsionales y accesorias de la pretensión principal, para la atención integral del menor discapacitado ${ }^{26}$. O cuando se trataba de la víctima de un accidente de trabajo que debía afrontar rápidamente una intervención quirúrgica ${ }^{27}$.

La tan prolífica cuanto proteica doctrina del exceso ritual ha servido, igualmente, para descalificar aquellas resoluciones omisas en la inobservancia del poder-deber de dirección y comando de la causa a cargo del juez (arts. 34 inc. $5^{\circ}, 36$ y conc., $\mathrm{CPCN}$ ), y que les impone la reconducción de las vías procesales, particularmente cuando de ello se derivare la violación de las garantías constitucionales del debido proceso y, más ampliamente, de la tutela judicial eficiente. Así cuando por apego a la literalidad del nomen iuris de las acciones, se obtura la tutela jurisdiccional en la vía procesal elegida, al declararse la inadmisibilidad sin, al mismo tiempo, posibilitar la reconversión para su trámite por el conducto que, iura novit curia, corresponda ${ }^{28}$. Claro que, en verdad, la reconducción de

25 SCBA, Ac. 98.260, 12-7-06, voto Dr. de Lázzari. Ac. 96.900, 6-6-07; Ac. 93.412, 2-11-05, entre otros.

26 SCBA, Ac. 90.868, 15-12-04.

27 SCBA, causa L. 93.463, 6-9-06.

28 En el criterio finalista de la C.S.N., la interpretación del art. 6 Cód. Contenc. Adm. provincial debe efectuarse de modo de evitar que los particulares queden fuera de la protección constitucional, en situación de indefensión, por manera que resulta "absolutamente irrazonable y lesiva de las garantías consagradas en el art. 18 Const. Nac., y por tanto descalificables como actos judiciales válidos", los pronunciamientos de la Casación de Buenos Aires que disponen en esas circunstancias el archivo de actuaciones, dejando sin aplicación el art. 352 inc. 1, C.P.C. de virtualidad supletoria según el art. 25 Cód. Contenc. Adm.. Así, entre otros, sent. 17-3-92, "Enrique Vanzetto S.A."; sent. 23-11-95, “Transporte del Oeste c. Municipalidad de 
las postulaciones se agota, en principio, en un proceso de selección de vías o tipos procesales regladas en el propio ordenamiento, de modo que no autoriza a canalizar aquellos por un carril diverso de construcción ex novo por el juez.

\section{EL CAMINO HACIA EL INFORMALISMO: EL RECURSO} INDIFERENTE Y LA DOCTRINA DE LA CSN EN EL CASO “YAPUR"

1. Habrá de convenirse que el principio de legalidad de las formas deviene de observancia estricta en el terreno de la impugnación de las decisiones judiciales. Las restricciones y condicionamientos legales a la admisibilidad de los recursos, tanto como los límites que encuadran la competencia legítima de los tribunales de alzada, se erigen en vallados insalvables. Sin embargo, por vía de la interpretación y con pié en la necesidad de tutelar eficazmente los derechos fundamentales se abren, como ya hemos visto, amplias brechas que posibilitan excepcionar aquellas restricciones legales, particularmente en punto a los requisitos formales de admisibilidad de los recursos, siguiendo una tendencia que se denota en la legislación comparada ${ }^{29}$.

2. Claro que no alcanzan, tales excepciones, a conformar lo que se denomina doctrina del recurso indiferente ${ }^{30}$, aquel que sin ser el que prescribe la ley expresamente para el caso (o que siéndolo, se han omitido requisitos formales), produce no obstante sus mismos efectos, respecto de la procedi-

Merlo". La C.S.N. ha aplicado el criterio general que permite reconducir los trámites procesales y el nomen iuris de las acciones, entre otros en asuntos de su competencia originaria (Fallos, 311:610; sentencia del 31-5-88, El Der., v. 129, p. 460, con nota de Bidart Campos G.J.).

29 Así, entre otras, las reformas introducidas al CPC colombiano, mediante el art. 51 del decreto 2651 de 1991, de flexibilización del recurso extraordinario de casación; y ahora confirmadas en el CGP de 2012 (arts. 333 y ss.). Claro que la admisibilidad juega en paralelo con el flujo siempre creciente de los recursos y la correlativa necesidad de buscar soluciones pragmáticas al fenómeno de la sobrecarga de los tribunales superiores, como las recetas del certiorari criollo (art. $280 \mathrm{CPCN}$ ), el filtro de la "repercusión general" de las cuestiones de la EC no 45/2004 brasileña, o de la "fundamental importancia" de la legislación alemana. OTEIZA E., La función de las Cortes Supremas en América Latina en Reforma procesal civil, E. Oteiza coord., AADP-Rubinzal Culzoni ed., Santa Fe, 2010, pp. 669 y ss. Asimismo, la reforma italiana de la ley del 18 de junio de 2009, n 69 (CARPI F., El acceso a la Corte de Casación en Cortes Supremas. Funciones y recursos extraordinarios, E. Oteiza coord., AADP, Rubinzal Culzoni ed., Santa Fe, 2011, pp. 17 y ss.).

30 Entre nosotros, por todos: FALCÓN E.M., Tratado de Derecho Civil y Comercial, RubinzalCulzoni ed., Santa Fe, 2009, v. VIII, pp. 88 y ss. Asimismo BARBOSA MOREIRA J.C., Comentarios ao Código de Processo Cvil, Forense, R. de Janeiro, 2005, 12a . ed., pp. 248 y ss. 
bilidad de la vía, a condición de que medien razones suficientes excusatorias del error incurrido, por ejemplo, la falta de claridad de la resolución impugnada o la existencia de jurisprudencia contradictoria sobre cuál fuere la vía pertinente.

Nuestros tribunales, salvo excepciones ${ }^{31}$, no han admitido, en general, la doctrina del recurso indiferente. En virtud el principio de unicidad de los recursos cada resolución judicial, como regla, tolera un solo carril de impugnación, de modo que las diversas vías no son fungibles ni intercambiables y, por tanto, no resulta procedente la interposición promiscua ${ }^{32}$.

3. En ese punto interesa analizar un singular precedente decidido por la CSN, en la sentencia del 28 de julio de 2009, en la causa "Yapur Elbio Alberto c. Caja de Previsión y Seguro Médico de la Provincia de Buenos Aires" ${ }^{\text {"33 }}$. Se trataba de una acción de amparo en la que se pretendía se dejaran sin efecto resoluciones administrativas que habían denegado al accionante una solicitud de pensión, por considerarlas violatorias de derechos fundamentales y convenciones internacionales en materia de igualdad de trato y no discriminación por elecciones sexuales. Contra la sentencia adversa de la Cámara Contencioso Administrativa platense se había deducido el recurso extraordinario de inconstitucionalidad provincial, el que fue denegado por la SCBA aduciendo que el remedio procesal interpuesto resultaba improcedente en el caso, toda vez que los agravios del apelante eran ajenos al carril promovido, y propios, en cambio, del recurso de inaplicabilidad de la ley.

Interpuesto el recurso extraordinario federal, que se fundamentara en la violación del derecho de defensa y la arbitrariedad de la sentencia por manifiesto exceso ritual al haber conferido primacía al nomen iuris del remedio procesal interpuesto, renunciando a la verdad objetiva, el Alto Tribunal hizo lugar a la queja y acogió el recurso extraordinario revocando la sentencia recurrida y mandando dictar nuevo pronunciamiento. Sostuvo, aplicando conocida doctrina, que si bien las cuestiones relativas a la admisibilidad de los recursos no son, en principio, revisables en la instancia extraordinaria, máxime cuando se trata de pronunciamientos de los superiores tribunales de justicia, tal principio reconoce excepción cuando, como en el caso, lo

31 El S.T.J. de Corrientes integra la falta de denominación de los recursos extraordinarios, en ejercicio de la atribución del iura novit curia, con sustento en la doctrina de la CSN del caso "Strada", del 8 de abril de 1986 que, según interpreta, impone al superior tribunal de la causa no detenerse en ese reparo formal sino suplir la omisión rotulando correctamente la impugnación y darle trámite (sent. del 9-8-2006, entre otras).

32 SCBA, 29-9-98; L-98.238, 11-11-09, entre otros.

33 Fallos, 332:1616. 
resuelto implica un exceso de rigor formal que lesiona derechos constitucionales invocados por el recurrente. Ello así, en tanto el sentenciador atendió a una cuestión formal, como es el nomen iuris de la vía utilizada, en desmedro del estudio de los agravios conducentes que ponían en tela de juicio temas de derechos fundamentales y planteaban cuestiones en orden a la aplicación e inteligencia de tratados internacionales en materia de discriminación. Máxime que, según su reiterada doctrina, en los casos aptos para ser conocidos por la Corte según el art. 14 de la ley 48, la intervención del ST de provincia es indispensable conforme el art. 31 de la CN, de modo que la legislatura local y la jurisprudencia de sus tribunales no pueden vedar con fundamentos formales el acceso, en tales supuestos, a aquel órgano (Fallos, 311:2478).

4. Parece claro el mensaje del Alto Tribunal: cuando están en juego derechos fundamentales "sensibles" con anclaje directo en la Constitución y los tratados de derecho humanitario - derechos y situaciones de tutela diferenciada-, y planteada oportuna y suficientemente la cuestión federal, se reserva la CSN la potestad de decir la última palabra al respecto, para asegurar las finalidades públicas de su cometido ${ }^{34}$. No es sino la aplicación de la doctrina "StradaDi Mascio" sentada por el propio Tribunal. Y la frustración de ese iter no puede nunca sustentarse en razones puramente formales, no solo porque se incurre en manifiesto exceso ritual, sino, principal y decisivamente, porque se impide el conocimiento de la Corte y, con ello, el ejercicio de sus misiones político-institucionales que reivindica como verdadero poder de Estado.

En esos supuestos, bajo el manto de la irrelevancia de las cuestiones formales, pierden entidad no solo el nomen iuris, sino aún el principio de unicidad de los recursos. La legislación, y hasta las Constituciones locales, deben posibilitar la intervención de un superior tribunal de la causa para que se pronuncie sobre las cuestiones federales planteadas, como instancia previa necesaria para la ulterior intervención de la CSN. Cuando la Constitución local -como, en el caso, la de la Provincia de Buenos Aires- no prevé un recurso extraordinario específico para canalizar el debate constitucional federal, que incluye los derechos fundamentales consagrados por las convenciones internacionales, el tribunal superior de la causa debe entrar a conocer y decidir habilitando cualesquiera de los recursos nominados, aun cuando tuviera fijada una doctrina legal diversa.

5. Es evidente que si el Alto Tribunal provincial no puede dejar de pronunciarse en tales supuestos, invocando razones formales, la doctrina sentada

34 TARUFFO M., Las funciones de las Cortes Supremas en Reforma procesal civil, Op. cit., pp. 649 y ss. OTEIZA E., Op. cit., pp. 669 y ss. 
por la CSN en "Yapur" implica consagrar el criterio del recurso indiferente, bien que con alcances amplios y peculiares. En efecto, la admisión formal del recurso no está supeditada a la existencia de laguna u oscuridad normativa que pudiere generar una duda razonable en el impugnante. No cabe entrar a discernir acerca de la existencia o no de razones suficientes que pudieren excusar el error incurrido. En "Yapur", la propia Constitución Provincial, al margen del opinable método que consagra en cuanto regula específicamente las causales que habilitan el conocimiento de la SCBA (art. 161), reserva el recurso extraordinario de inconstitucionalidad -el único deducido en el caso - tan solo y taxativamente para denunciar la invalidez de preceptos locales de cara a la Carta provincial, de modo que formalmente el planteo efectuado era improcedente-. No mediaba entonces oscuridad alguna en los textos, ni doctrina contradictoria (la propia SCBA desde antiguo enmarcó la denuncia de la inconstitucionalidad federal en el recurso de inaplicabilidad de ley o doctrina legal). Hubo error inexcusable en el recurrente pero militaban en el caso excepcional planteado ${ }^{35}$ las razones superiores que invocó la Corte, vinculadas a la efectividad del control de constitucionalidad y la supremacía del art. 31.

\section{FORMAS Y PROCEDIMIENTOS DE CREACIÓN PRETORIANA}

No son pocos los ejemplos que revelan el activismo de los jueces que, trascendiendo la pura interpretación normativa limitada a esclarecer el sentido y alcances de la preceptiva formal, se adentran en la articulación creativa pretoriana de nuevas vías, procedimientos y formas en general. Así se gestaron en Argentina la acción de amparo, la acción declarativa de inconstitucionalidad, la doctrina de la arbitrariedad y del exceso ritual manifiesto, la acción de tutela de los derechos individuales homogéneos, el régimen singular de manejo de los proceso de interés público, junto a otros más modestos aunque no menos significativos por su operatividad práctica ${ }^{36}$, como las distintas tutelas anticipadas y de urgencia, entre otras.

35 Se ha sostenido, concordantemente, que en casos excepcionales cabe aplicar el principio de fungibilidad, aunque la parte manejó inadecuadamente el instrumento procesal, descuidando la forma prevista por el legislador, aun no habiendo duda, laguna u oscuridad en el sistema. Si la forma no puede perjudicar el ejercicio del derecho, incumbe al juez conceder la medida más adecuada a la situación concreta de la causa (BARROS TEIXEIRA G.F. de, Principio da fungibilidade: rumo a "desformalizaçâo" do processo en Bases científicas para un renovado Direito Processual, ed. IBDP 50 anos, organ. Guzmâo Carneiro A. y Calmón P., Brasilia, 2008, v. I, pp. 143 y ss., especialmente pp. 161-162).

36 BERIZONCE R.O., "Tutelas procesales diferenciadas", Op. cit., passim; id., Activismo judicial y participación en la construcción de las políticas públicas en RDP número extraordinario El Derecho Procesal en vísperas del Bicentenario, 2010, pp. 169 y ss. 
A esa extensa nómina cabe agregar recientemente la figura del "abogado del niño", con la finalidad de patrocinar a los menores en ciertos supuestos en que se les reconoce el carácter de parte, y cuyos contornos comienzan a delinearse. Se trataba de una causa promovida con el objeto de obtener el cese del régimen de visitas a favor del padre bajo acusación de abuso sexual, en la que al conocer en vía del recurso extraordinario federal, la CSN dispuso se proceda a designar un letrado especializado en la materia para que patrocine a los menores, a los efectos de atender primordialmente al interés del niño y con el objetivo de que aquellos sean escuchados con todas las garantías", a fin de que puedan hacer efectivos sus derechos ${ }^{37}$. De ese modo, se ha dotado a los niños de un patrocinio letrado ad hoc, a cargo de un abogado especializado, que viene a integrar una figura procesal novedosa, similar por los objetivos que persigue a la que el ordenamiento procesal contempla en el art. 626 inc. $1 \mathrm{CPCN}$, para la defensa ad litem de los presuntos incapaces, sin perjuicio de la intervención necesaria que en ambos supuestos corresponde al defensor oficial.

La fuerza creativa de los jueces, expresada en tantos segmentos del proceso a través de un movimiento continuo se ve impulsada, parece evidente, por la inercia cada vez más pronunciada del legislador. No en vano nuestro ordenamiento mayor de 1967, no solo no se ha modificado estructuralmente, ni siquiera ha sido actualizado para dar cabida a las múltiples creaciones avanzadas por la jurisprudencia. En ese contexto, como se ha afirmado ${ }^{38}$, el poder de adecuación procedimental del juez no está restringido a las normas procesales abiertas, toda vez que la falta de previsión legal de la técnica procesal idónea para la tutela del derecho material o incluso la fijación de la técnica procesal idónea, obligan al juez a identificar aquella que resulte adecuada a partir del derecho fundamental a la tutela judicial efectiva.

\section{LA SIMPLIFICACIÓN Y LOS CONFINES DE LA DESFORMALIZACIÓN DEL PROCESO CIVIL}

Conviene ahora retomar el principio de legalidad de las formas, detraer los supuestos de flexibilización y concesiones ya analizadas: i) potestades judiciales explícitamente contenidas en el propio ordenamiento legal para seleccionar tipos o formas procesales; i.i.) doctrina pretoriana del exceso ritual manifiesto; i.i.i.) doctrina pretoriana del recurso indiferente; i.i.i.i.) creaciones pretorianas de formas y procedimientos especiales; y plantear un último pero no menos

\footnotetext{
37 CSN, 26-10-10, “G., M.S. c. J.V., L.”, La Ley, 2011-A, p. 215, con nota de R.G. Jáuregui.

38 MARINONI L.G., El proceso en el Estado constitucional, Op. cit., pp. 203; id., Aproximación crítica entre las jurisdicciones del civil law y del common law..., RDP, 2013-2, pp. 526-527 y ss.
} 
importante interrogante sobre el sentido y alcances de la desformalización del proceso. Parece evidente que todas esas concesiones suponen, cuanto menos, la paulatina difuminación de aquel principio esencial del formalismo; sin embargo, no es menor cierto que el sistema de la legalidad conserva amplios e infranqueables espacios de operatividad.

Si bien se ve, resulta fundada a la luz de nuestra experiencia jurisprudencial la afirmación de que a partir del principio de instrumentalidad (con el soporte de la garantía fundamental del debido proceso y, ahora, de la tutela judicial eficiente), se ha venido desenvolviendo al socaire de una interpretación pretoriana creativa no solo el aspecto negativo y bloqueador que constituye el fundamento de la doctrina del exceso ritual, sino, además, lo que calificadamente $^{39}$ se ha denominado su vertiente positiva, su operatividad para posibilitar al juez, sin caer en un "alternativismo" descontrolado, conducir el proceso hacia sus fines institucionales (jurídico-político-sociales), en los diversos ámbitos de las garantías fundamentales. El gran desafío del legislador y del juez reside en la construcción de técnicas procesales capaces de tutelar de modo efectivo los derechos materiales, según su naturaleza y peculiaridades. La configuración de los procesos colectivos, tanto como las tutelas diferenciadas o los litigios de vecindad constituyen una deuda pendiente del legislador, lo que legitima el protagonismo judicial. Los jueces integran el gobierno del Estado y son responsables directos de la tutela efectiva de los derechos cuando se requiere su intervención por haber sido vulnerados.

La búsqueda incesante de procedimientos más accesibles y, con ello, más simples y racionales, más económicos y eficientes para la solución de los conflictos, que alientan universalmente todos los programas de reformas ${ }^{40}$, se sustenta en diversos ejes que confluyen en la idea de la simplificación del proceso. La efectiva simplificación presupone que las reglas procesales sean adecuadamente flexibles o elásticas ${ }^{41}$. Claro que ello no significa admitir la postura extrema que conduciría a la abolición de toda regla general, dejando librado al juez la atribución de dictar las disposiciones adecuadas en cada caso. Lejos se está de admitir la idea del proceso "a medida" librado al solo arbitrio judicial. No solo se oponen a ello las normas constitucionales sino, también, las reglas de las convenciones internacionales sobre la tutela judicial

39 DiNAMARCO C.R., A instrumentalidade do processo, Manheiros, Sâo Paulo, 1996, 5a. ed., pp. 267 y ss.

40 The reforms of Civil Procedure in comparative perspective, ed. N. Trocker y V. Varano, G. Giappichelli, Torino, 2005, openning remarks, pp. 2 y ss., passim.

41 BIAVATI P., Tendencias recientes de la justicia civil..., Op. cit., pp. 529 y ss.; id., Argomenti..., Op. cit., donde se alude al proceso con estructura elástica, pp.100-102. 
que estatuyen un nivel suficiente de garantías, de corrección y previsibilidad de las reglas de juego formales ${ }^{42}$.

Los valiosos objetivos que predica la doctrina moderna de desformalización y "desacralización" del proceso ${ }^{43}$ son perfectamente compatibles, en cambio, con la idea de elasticidad o flexibilización de las normas, como camino para armonizar reglas legales predeterminadas y previsibles, por un lado, y las peculiaridades del caso individual, por otro. Las normas elásticas preveen una pluralidad de posibilidades en relación a diversas y eventuales connotaciones del caso concreto, entre las cuales el juez selecciona la más apropiada. Así, las Civil Procedure Rules inglesas de 1998 estructuran diversos tipos procesales atendiendo a la complejidad del litigio, small claims, fast track y multitrak litigation; o en el CPC italiano, la norma flexible del art. 281-sexies, CPC, que prevé la posibilidad de tres modalidades diversas (oral, escrita o mixta) de la fase decisoria del proceso ${ }^{44}$. Todavía, una mayor dosis de flexibilidad y versatilidad se contiene en los procesos sumarios o simplificados regulados en los arts. 702 bis, 702 ter y 702 quater del ordenamiento italiano, introducidos por la ley 69/2009, en los cuales se confiere al juez un amplio margen de discrecionalidad, pudiendo proceder en el modo más oportuno a los actos de instrucción relevantes al objeto del proveimiento, con la sola condición de observar las formalidades esenciales del contradictorio ${ }^{45}$. En línea con esas ideas, el art. 51 del Reglamento (CEE) 861/2007, regulador del procedimiento europeo de escasa cuantía, dispone que será escrito, sin perjuicio de que el órgano jurisdiccional celebre una vista oral si lo considera necesario o si una de las partes así lo solicita; solicitud que puede ser desestimada si la vista oral resulta a todas luces innecesaria para el correcto desarrollo del procedimiento ${ }^{46}$. En el derecho argentino, una variante de tal tendencia se advierte en las leyes de amparo; así entre otros, en el régimen bonaerense se prevé como pauta general que los jueces están facultados para acelerar el trámite, mediante formas más sencillas que se adapten a la naturaleza de la cuestión planteada (art. 25 ley 13.928, modificado por ley 14.192).

$42 \quad$ BIAVATI P., Op. cit., pp. 538 y ss.

43 PELLEGRINI GRINOVER A., Desformalizacâo do processo... en Novas tendências do Direitto Processual, FU, R. de Janeiro, 1990, pp. 175 y ss.

44 BIAVATI P., Op. cit., pp. 540 y ss. CARPI y TARUFFO, Commentario breve al Codice di Procedura Civil, Cedam, Padova, 5ª . ed., 2006, pp. 821 y ss.

45 Como señala BIAVATI, el deber de prognosis que la ley confía al juez implica una suerte de case management italiano, similar a la potestad reconocida al juez inglés (Apuntes introductivos..., Op. cit., p. 556-557; id., Argomenti..., Op. cit., pp. 100 y ss.).

46 BONET NAVARRO J., La introducción del material fáctico en el proceso civil... en Derecho Procesal Contemporáneo. Ponencias..., Op. cit., v. I, pp. 233-234. 
Claro que, como se ha observado agudamente ${ }^{47}$, la objeción teórica fundamental respecto a la elasticidad o versatilidad del trámite es la falta de previsión precisa de su desarrollo. Sin embargo, a salvo sustancialmente el derecho de defensa y la garantía del contradictorio, un esquema más flexible no puede merecer objeciones. Ha de partirse de la base que la estructura básica del procedimiento siempre proviene de la ley y que lo que se delega al juez es el poder restringido de adecuar, como método, aquel esquema estructural de la ley para la mejor y más oportuna obtención de los fines del proceso. Bien que sin dejar de lado y observando siempre lo que constituye la esencia, el "núcleo duro" de la garantía del debido proceso. Los esquemas simplificados o sumarios, que constituyen la "niña bonita" en la búsqueda de un proceso justo con todas sus connotaciones, presuponen la salvaguarda de aquellos principios y valores de base entre los cuales se destaca el contradictorio de las partes; con esa salvedad, le está consentido al juez regular, adecuar ${ }^{48}$, flexibilizar y hasta omitir cualquier formalidad que no resulte esencial, precisamente, al contradictorio. Como se ha señalado ${ }^{49}$, en un proceso simplificado y flexible ambas proposiciones se presuponEn: el trámite puede ser simplificado porque es elástico, flexible, dúctil, lo que permite al juez adecuarlo a los casos particulares según sean las características constitutivas de los derechos y situaciones en debate; y puede ser elástico porque la estructura de base es suficientemente simple (en cuando fundada, en definitiva, en la mera garantía de la defensa) para poder ser llenada por la flexibilidad. Claro que esta doble condición presupone un papel activo del juez, sin el cual la simplificación de los trámites resulta ilusoria.

En verdad, en la alternativa proceso rígido-proceso flexible confluyen no solo el principio de legalidad de las formas, la instrumentalidad y la adecuación, sino además y a un mismo tiempo, los demás principios y reglas procesales: dispositivo y su atenuación por los poderes-deberes conferidos al juez para la dirección del proceso, contradictorio, economía procesal, de trámites, de costos (incluyendo el "máximo rendimiento"), probidad y buena fe, etc., todos los cuales, a su vez, se enlazan y complican para poder brindar, a través de un proceso "de resultados", la tutela judicial efectiva de los derechos.

47 BIAVATI P., Tendencias recientes de la justicia civil..., Op. cit., p. 541.

48 TARUFFO M., Orality and writing as factor of efficiency in civil litigation en Oralidad y escritura en un proceso civil eficiente. Ponencias generales e informes nacionales, coord. F. Carpi y M. Ortells, Univ. de Valencia, Valencia, 2008, p. 204, donde se propicia dejar librado al juez establecer, caso por caso, si el trámite ha de ser oral o escrito. En el mismo sentido: BONET NAVARRO J., Op. cit. pp. 233-234. 


\section{Conclusiones}

Estamos ahora en condiciones de subrayar las siguientes conclusiones:

1) El clásico principio de legalidad de las formas, sustentado en elementales razones de seguridad jurídica y la garantía del contradictorio de las partes, ha evolucionado paulatinamente por influjo de diversas pautas de flexibilización, expresadas sea a través de la instrumentalidad o finalismo, con sus consectarios, ya por numerosas creaciones pretorianas de nuevas formalidades de los actos, y trámites y procedimientos articulados a partir de la interpretación normativa, aún ex novo, para su adecuación a las particularidades de las materias sustantivas.

2) La doctrina pretoriana argentina del exceso ritual manifiesto, en el marco de la arbitrariedad de sentencia, constituye una venturosa y fructífera aplicación del principio de instrumentalidad, expandida desde la CSN y de aplicación por todos los tribunales del país, que no solo ha resultado de significativa utilidad para combatir la desnaturalización de las formas y el formulismo, sino además, para brindar sustento a la interpretación creativa que permitiera perfilar más adecuadamente diversos principios procesales, como el dispositivo, contradictorio, de economía procesal, de probidad, de buena fe y colaboración, entre otros.

3) La consagración y reconocimiento del derecho fundamental a la tutela judicial eficiente, especialmente desde su incorporación a la $\mathrm{CN}$ argentina reformada y a los pactos internacionales sobre derechos humanos que la integran, ha impuesto un replanteo general de los pilares en que se sustenta todo el Derecho Procesal, en especial, las teorías de la jurisdicción, la acción y el proceso, con virtualidad directa sobre el régimen de las formas procesales. La concepción de la jurisdicción como función pública esencial con la consecuente jerarquización de la magistratura en su misión tuteladora de los derechos fundamentales; de la acción como medio irrestrictamente abierto para dicha tutela; y del proceso como instrumento al servicio del reconocimiento y operatividad de los derechos sustantivos, "de resultados" concretos, influyen notoriamente sobre el principio de legalidad formal.

4) Los modernos postulados de adecuación de las formas, y aún de "desformalización", han de conjugarse armoniosamente con el principio de legalidad, desde que resultan perfectamente compatibles; todo ello con la finalidad esencial de simplificar los desarrollos litigiosos, presupuesto indeficiente de la tutela judicial efectiva.

5) La simplificación de las formas, a su vez, presupone que las reglas procesales sean adecuadamente flexibles, elásticas. No se trata de dejar libradas al 
arbitrio judicial la fijación de las reglas en cada caso particular, sino de conceder a los jueces atribuciones limitadas para discernir razonablemente en el marco acotado de diversas posibilidades, con la finalidad de seleccionar las vías más adecuadas en atención a la mayor o menor complejidad fáctica de los conflictos. Bien que condicionado a la estricta observancia de las garantías del debido proceso y del contradictorio de las partes, siguiendo las líneas tendenciales que se evidencian en la legislación comparada.

6) El fenómeno general y la tendencia a la adecuación de las formas y simplificación de los trámites, se manifiesta de modo preponderante y notorio en el cuadrante de los derechos fundamentales "sensibles" generadores de tutelas procesales diferenciadas, para brindar sustento a la denominada "justicia de acompañamiento" o "de protección".

\section{REFERENCIAS}

ALEXY R., Teoría de los derechos fundamentales. Centro de Est. Polit. y Const., Madrid, 2002, 3a. reimpresión, trad. E. Garzón Valdés, pp. 454-459.

BARBOSA MOREIRA J.C., Comentarios ao Código de Processo Cvil, Forense, R. de Janeiro, 2005, 12a . ed., pp. 248 y ss.

BERIZONCE R.O., Tutelas procesales diferenciadas, Rubinzal Culzoni ed., Santa Fe, 2009, passim.

BERTOLINO P.J., El exceso ritual manifiesto, LEP, La Plata, 2003, 2ª ed., passim.

BIAVATI P., Tendencias recientes de la justicia civil en Europa, RDP 2008-1, p. 540; id., Argomenti di Diritto Processuale Civile, Bonomia Univ. Press, Bologna, 2011, pp. 100 y ss.

CADIET L., Las nuevas tendencias del procedimiento civil en Francia en Reforma procesal civil, E. Oteiza coord., AADP, Rubinzal Culzoni ed., Bs. As., 2009, pp. 109-111.

CAPPELLETTI M., El testimonio de la parte en el sistema de la oralidad, LEP, La Plata, 2002, trad. T.A. Banzhaf, parte primera, pp. 271 y ss. DENTI V., Estudios de derecho probatorio, Ejea, Bs. As., 1974, trad. S. Sentís Melendo y T.A. Banzhaf, pp. 1009-118.

DINAMARCO C.R., A instrumentalidade do processo, Manheiros, Sâo Paulo, 1996, 5ª. ed., pp. 267 y ss.

FALCÓN E.M., Tratado de Derecho Civil y Comercial, Rubinzal-Culzoni ed., Santa Fe, 2009, v. VIII, pp. 88 y ss. 
JOLOWICZ A., Il nuovo ruolo del giudice del "pre-trial” nel processo civile inglese en RTDePC, 2003, p. 1263. BARBOSA MOREIRA J.C., Uma novidade: o Código de Processo Civil inglês en Temas de Direito Processual, Sétima Série, Saraiva, Sâo Paulo, 2001, pp. 179 y ss. ANDREWS N., Relaçôes entre a Corte e as partes na era no case management, en RePro, n ${ }^{\circ} 217,2013$, pp. 181 y ss.

GILLES P., El proceso civil en transformación..., RePro, Sâo Paulo, nº 173, 2009, pp. 330 y ss.

MARINONI L.G., "El proceso en el Estado constitucional”, en Rev. Peruana de Derecho Procesal, Communitas, Lima, 2010, trad. Ch. Delgado Suaréz, pp. 177 y ss.

Teoría geral do processo, E. dos T., Sâo Paulo, 2006, pp. 101-139; 451-467. ZANETTI Jr. H., O modelo constitucional do processo civil brasileiro, Lumen Juris, R. de Janeiro, 2007, pp. 177-184.

MORELLO A.M., Constitución y proceso..., Abeledo-Perrot, LEP, Bs. As., 1998, passim; id., La eficacia del proceso, Hammurabi, Bs. As., 2001, 2a.ed., passim; id., El proceso justo, Lexis Nexis, LEP, Bs. 2005, 2a. ed., pp. 335 y ss.

PALACIO L.E., Derecho Procesal Civil, Abeledo-Perrot, Bs. As., 1972, v. IV, pp. 144-145.

PELLEGRINI GRINOVER A., Desformalizacâo do processo... en Novas tendências do Direitto Processual, FU, R. de Janeiro, 1990, pp. 175 y ss.

TARUFFO M., Las funciones de las Cortes Supremas en Reforma procesal civil, Op. cit., pp. 649 y ss. 